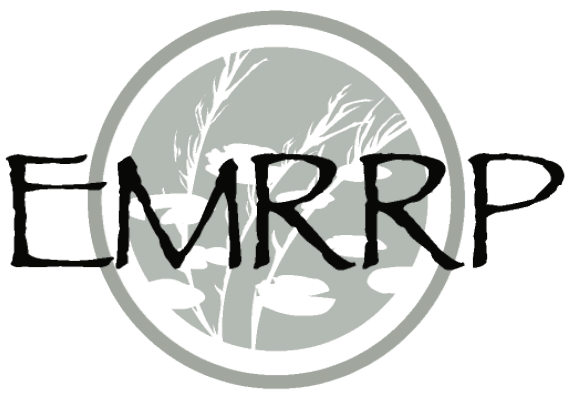

\title{
Tools for Predicting Wildlife Species Distribution Response to Ecological Shifts
}

by Austin Davis, Ashley Fuentes, Jacob F. Jung, Heather Theel, Eric Britzke, and Richard A. Fischer

INTRODUCTION: The U.S. Army Corps of Engineers (USACE) serves as the Nation's environmental engineer. Within this capacity, the USACE designs, plans, oversees, and manages multiple civil works and military construction efforts. The advancement of sustainable design and development practices that beneficially integrate engineering and ecology is a goal of USACE projects (https://ewn.el.erdc.dren.mil/About.html). Once completed, USACE projects are often in service for many decades; therefore, USACE planners must consider long-term changes in the environmental setting of each project (Cann 2010). Wildlife distributions change over time in response to the gain and loss of habitat, as well as other natural processes. Regulatory actions, such as the designation of critical habitat under the Endangered Species Act, can allow for habitat to be preserved promoting source populations that can expand their distribution if conditions are favorable. The listing or de-listing of Threatened and Endangered Species can have direct impacts on USACE projects coming to fruition after years of planning. In an effort to predict potential impacts to USACE restoration sites from species range shifts either into or out of an area, this technical note provides a methodological framework and promotes a model design that has the capacity to inform future decision making.

PURPOSE: This effort will develop a working model that can serve as a tool to predict range shifts of threatened, endangered and at-risk species (TER-S), as environmental conditions are altered by climate change (CC). This tool will assist the USACE with future planning and preparation for restoration projects that incorporate management for TER-S already present within the North Atlantic Division (NAD). Changes in climate have an impact on a wide variety of components within natural environments. Temperature and precipitation changes impact vegetation phenology that may disrupt ecosystems in a way that changes TER-S habitats. With the wide breadth of potential impacts from $\mathrm{CC}$, earlier efforts have focused on developing tools for specific circumstances and/or impacts. However, as each of these factors change independently to impact other components, a more comprehensive methodology is needed to conduct a robust assessment of the impacts of CC across a variety of situations and locations.

Models that display where TER-S are currently located, and to what extent these range shifts will occur, will be of great importance towards future project planning and resource management. Britzke et al. (2014) outlines existing research products for physical upland climate drivers (e.g., precipitation, temperature, land classification) that are suitable for delineating biome shift vulnerability. For example, some TER-S are strongly associated with specific vegetation communities and forecasting vegetation dynamics can be causally linked to TER-S ranges. Typically, these approaches used species distribution and regression models to statistically 
understand changes to spatial ranges given a variety of factors. Many dynamic process models focus on individual processes (i.e., sea level rise, erosion, movement) independent of the forcing's provided by other processes. However, emergent approaches allow for incorporation of many different processes to capture interdependencies present within the system. These approaches allow for an investigation of the most important process drivers for ecological transformation.

Understanding Drivers of Change. An ecological system consists of both biotic and abiotic components within the environment that are interconnected, and in which, species interact. These systems adapt and evolve as natural processes function throughout time on the landscape. Solar loading, atmospheric chemistry, anthropogenic processes, and hydrology all work to transform landscapes to support the dynamic processes of ecological systems (Moss et al. 2010; IPCC 2007). Research in spatial ecology has provided understanding of the role space and time play within these dynamic systems (Turner 1989; Watt 1947), and has led directly to the development of many different models. Each model represents the expert perspective of the modelers for solving problems or understanding dynamic processes at work. As ecological systems undergo continual transformation, the resident species that depend on these systems are forced to adapt, relocate, or perish (Beaumont et al. 2008; Walther et al. 2002). This systemic pressure on wildlife to respond to ecological change leads to spatial changes in the distribution of the species. For many species, these changes in species distribution over time have been documented (Chen et al. 2011; Beaumont et al. 2008; Donoghue and Edwards 2014; Twidwell et al. 2014a; Walther et al. 2002). Further, for current species distributions, climatological and ecological setting are important factors to consider when predicting future shifts in species distributions (Beaumont et al. 2005).

Computational dynamic geographical models are frequently used to understand the complexity of ecological processes occurring on the landscape. These models can assess drivers such as temperature, precipitation, solar loading, and atmospheric chemistry. There are a variety of models used to assess dynamic changes in temperature and precipitation over landscapes with varying degrees of inputs (Real et al. 2010; Twidwell et al. 2014a; Twidwell et al. 2014b; Britzke et al. 2014; Beaumont et al. 2008; Moss et al. 2010), however, there is no single best climate model to cover all geographic regions as each model caters to specific areas (IPCC 2007) and is used for specific purposes. Confidence in each model is obtained through the following three factors: (1) physical scientific laws and observations, (2) the capability to simulate important characteristics within the current environment, and (3) the ability of the model to reproduce past environmental responses to changes in variable climate (Giorgi 2005; Randall et al. 2007).

Guiding Decisions. Scientific modeling informs many decision-making processes related to project planning within the USACE. These models are especially useful in situations where decisions are applied to complex systems of interdependent processes that are difficult to fully comprehend. The decomposition of these complex systems into more atomic components provides a way for planners and decision makers to deal with the outcomes of a concurrent system of processes. Many dynamic geographical models are limited both temporally and spatially. For the purposes of this work, limits are placed on the consideration of the spatial bounds of the USACE North Atlantic Division. The typical time frame for a climate dependent ecological model is around 30 years (Britzke et al. 2014); however, some models, when used for environmental sensitivity investigations, can continue to produce predictions over hundreds and thousands of years (Moss et al. 2010). Models must be selectively chosen depending upon the research question and the desired output. In the next 
section, an overview of data and model considerations for choosing an appropriate methodology for understanding species distribution responses to changing ecological setting are provided.

Background Review of Tools and Data. When conducting a model driven investigation of the dynamic transformations of ecological settings, it is important to first understand the climatological setting that affords the current ecological regime. Further, the geographic bounds of an investigation area must also be considered to ensure that any selected model has access to relevant data throughout the geographic coverage area. Next, a model selection decision is made to ensure an appropriate model is used. Available model methodologies include integrated assessment models, climate models, and impacts, adaptation, and vulnerability assessments, as well as many others not mentioned here.

Publically Sourced Data. A model will take one or more inputs over a selected spatialtemporal extent, to produce an output that can be interpreted and reported (Britzke et al. 2014; Pultar 2009). Data needed for model inputs can often be obtained from numerous organizations. NatureServe is a non-profit organization supported widely by several government agencies and other organizations (NatureServe 2017). Different tools are offered to the general public which can be used to provide a baseline of data for models; examples of such tools are NatureServe surveyor, CC vulnerability index for ecosystems/habitats, NatureServe explorer, maps of current at risk species, and crucial habitat assessment tools (NatureServe 2017). Another predominant publically available data source is climatewizard.org. Similar to NatureServe, this organization is used by a wide variety of government and non-government organizations to provide baseline data for climate dependent models (Girvetz et al. 2009). Climatewizard.org provides a range of climate scenarios at various temporal scales. When this data is coupled with Atmosphere-Ocean General Circulation Models, the user is able to consider different hypotheses about the effects that oceans and atmospheric processes have on terrestrial climate (Randall et al. 2007).

Integrated Assessment Models (IAMs). A diverse selection of models has already been created and others are currently being developed (Moss et al. 2010; IPCC 2007; van Vuuren etal. 2009). Integrated assessment models (IAMs) are primarily used for the representation of human influences on the environment. Some have integrated different climate aspects into their framework such as temperature and precipitation; however, a true IAM integrates multiple frameworks into one single model. For example, data from climate, energy use, land use, and air pollution models may be coupled together to create one model output (Schwanitz 2013; Moss et al. 2010). IAMs are useful when creating a system which is further used to evaluate influences of $\mathrm{CC}$ on the environment and predict areas of concern within the scope of the model.

Climate models. Climate models represent natural systems and the possible effects of atmospheric change induced by both natural and anthropogenic sources for a given study area (Moss et al. 2010). There are a variety of different climate models that provide different information depending on the amount of precision or accuracy the research output requires.

At a large scale, earth system models offer information pertaining to geological processes as well as ecological impacts (Moss et al. 2010). These models assimilate climate influences along with ecological diversity data, allowing the researcher to investigate the broad scope of CC and its impacts on a representative earth as a whole (Poulter et al. 2011). 
General Circulation Models incorporate the effect of the biogeochemical cycles on climate, in particular atmosphere-ocean models provide estimates of $\mathrm{CC}$ including extreme weather events (Moss et al. 2010; Randall et al. 2007). Regional climate models study climate at a much smaller scale than most others, they focus on certain areas such as microclimates or individual states. Regional models requires the user to refine their output products to a much finer resolution and spatial scale, in order to gain more accuracy during the estimation of future climate (Teutschibein and Seibert 2012).

Finally, Simple Climate Models provide outputs at a coarse spatial scale. These models help to explore the various uncertainties in modelling climate as well as assist in the development of IAMs (Moss et al. 2010). Even at a coarse spatial scale, Simple Climate Models are valuable for determining the effects that greenhouse gases pose to the atmosphere, the global surface temperature as a result of radioactive forcing, and projections about changes in mean sea level (Randall et al. 2007).

Impacts, Adaptation, and Vulnerability. Impact models allow the user to predict the effects of $\mathrm{CC}$ on a given ecosystem or species (McCarthy et al. 2001). They readily provide estimated information in regards to the desired system and any fluctuations within the population or climate. Various models can be used to assess any foreseen or predicted impacts, ranging from biophysical characteristics and environmental processes to socio-economic and population growth models (Klein 2004; Moss et al. 2010). Impact models provide a reference and evaluation tool for policy and decision makers that supports their efforts in assessing risks associated with CC. Adaptation and vulnerability are both risks that can be calculated through an impact model. Evolution and adaptation are both driven by environmental factors, therefore, it can be assumed that each is partially determined by fluctuating climate (Hoffmann and Sgro 2011). When correlating species vulnerability with current and projected climate, a susceptibility analyses tool is used (Britzke et al. 2014). This can be further applied to environmental management actions and used in estimating the accumulated risk for each species dependent upon future climate (Dale et al. 2001; Foden et al. 2008).

Species. Species distribution models (SDM) are able to assess impacts of climate on species distributions over time (Heikkinen et al. 2006). SDMs are also used to assess current and future conservation strategies, as well as the extinction probability of a given species under future climate scenarios. The results from these model allow researchers to anticipate which areas a particular species may occupy given future climate conditions (Beaumont et al. 2005). SDMs use different assumptions to create rules that aid in the model's decision recommendation abilities. The most common assumption used for SDMs is understanding that climate will ultimately limit where and when a species will survive or perish (Heikkinen et al. 2006; Thomas 2010). One widely used model is the BIOCLIM correlative model; it utilizes 35 different climate parameters over a given species range (Beaumont et al. 2005). A known concern of this model is its ability to over-fit a species to a give future location; this occurs when too many parameters are applied in a scenario, forcing the output to be an over-restrictive predicted area (Beaumont et al. 2005).

Biome and Niche. Ecological niche models, also known as ecological site descriptions (ESD), combine a variety of environmental variables with current species distributions to predict how habitats may transform under future climate scenarios (Araujo et al. 2005; Real et al. 2010; Heikkinen et al. 2006). Most ESDs use data derived from monthly and annual precipitation and 
temperature averages over specific regions; however, it is challenging to rely solely on this data to predict habitat variation since these averages cannot represent small spatial extents within an ecological site (Twidwell et al. 2014a). Developers of ESDs usually focus on drivers of change that have been present in the recent past. These drivers make ESDs highly subject to bias, leading to a wide range of interpretations of the prediction of climate effects on different vegetation (Twidwell et al. 2014a).

Handling Uncertainty. Any form of modeling comes with limitations and uncertainties. While each model has its own restrictions, there are general limitations and uncertainties within every model. Common actions that can reduce model uncertainty are the following: identify and use the appropriate climate model that produces the desired output, selecting an appropriate climate scenario, using climate scenario assemblages as an average to filter out any possible bias, running probability distributions to provide a range of values for probable range/species shift, and using idealized scenarios for areas in the model that are less than ideal (Beaumont et al. 2008). However, there will always be a degree of uncertainty when predicting an environment which has yet to occur, that ultimately is a side-effect of basic model assumptions and current scientific understanding.

Climate models achieve different results based on the data available, scenarios used, and desired outcomes. Some causes for differences in model outputs are due to the lack of, or limited use of, computational power (Beaumont et al. 2008), fundamental basics of the climate models, and/or the representation scheme used for the laws of physical climate processes. Discrepancies in the output could be linked to the misunderstanding of fundamental basics or incorrect parameterization of given processes (Beaumont et al. 2008; Curry 2014). Many temperature models do notaccount for temporal changes, since the majority use uniform change in climate variables (Beaumont et al. 2008). Another aspect of the uncertainty in climate models is the variation in atmospheric circulation (Overland and Wang 2010). Atmospheric circulation refers to the annual change in air temperature occurring independent of the earth's surface immediately beneath. Typically there are two main causes of this, chaotic natural variability, and global oscillations. When atmosphere and surface interaction is modeled, these variabilities often explain certain aspects of model error (Shepherd 2014). Natural variability is what would occur in the environment had there been no inputs from anthropogenic sources; likewise, chaotic natural variability is any action which creates an abnormal situation on a large time scale such as a volcanic eruption (Overland and Wang 2010; Shepherd 2014). The chaotic natural variability is challenging to predict and will result in skewed products if not accounted for in a model. The spatial representation of features within a climate model is another common cause of uncertainty. This characteristic, known as the Modifiable Area Unit Problem, commonly biases statistical differentiation of spatial information (Shepherd 2014).

Species, Biome, and Niche. Species distribution models (SDM) predict where a species will move in future generations, requiring extensive knowledge of that particular species and their environmental interactions. For mobile species, the distribution requires extensive knowledge of biochemical processes within the individual, and the traits of that species and the landscape in which they live. There are various contributing factors that affect the uncertainty of SDM projections. Climate affects species interactions by changing environmental parameters necessary for reproduction and habitat. Ecological setting can also have a direct impact on individual behaviors associated with population growth or decline (Thomas 2010). These factors are all involved in the distribution of a species; when not accounted for in a SDM project, these factors can lead to extreme 
bias and error (Thomas 2010). The time involved for a species to readjust and react to changing environments is a data gap common in SDMs; this is more common in the resident species that experience their lifecycle at a single location (Thomas 2010; Chen et al. 2011).

Landscapes can change for a variety of reasons, but the variability of resident ecology often serves as a recognizable boundary to characterize different biomes and sub-biomes (Donoghue and Edwards 2014). Many models calculate biome movement through only climate parameters, such as temperature and precipitation. Not all biomes are equally situated on earth, generally biomes transform into an adjacent biome instead of relying solely upon environmental parameters. These transformations and movements are fueled by species interactions and species' abilities to outcompete dominant species within a new area (Ackerly 2003). Uncertainty in spatial extents and temporal lag time often results in model bias and error when predicting changes in land cover or biome delineation. Spatial extent is essential for mapping land cover because it is the defining aspect of any boundary, however if the dataset is world-wide (such is the case with many climate datasets), a downscaling procedure must be applied to use the data in a particular area, diminishing its precision and accuracy (Twidwell et al. 2014b; Gonzalez et al. 2010).

FRAMEWORK DEVELOPMENT: Assessing ecological shifts based on atmospheric, anthropogenic, or geologic drivers is often accomplished through the use of geographical dynamic models. Geographical dynamic models often use an iterative approach to modify data, such that over a set of intermediate temporal representations, temporal changes can be understood. Alternatively, a logical ordering of events can be used, instead of discrete time steps, to represent the temporal changes that occur on the landscape. Using a series of discretized events, as opposed to discrete time steps, can lead to computational improvements and reduce execution times, as computation is only necessary when changes must occur based on the conceptual model of the system.

Given the need for a geographic dynamic modeling solution to understand the potential drivers of expected ecological change on the landscape, a framework is needed that assesses such change given a set of working assumptions of the computable aspects of the environment. Further, given the geographic scales involved, it is infeasible to represent the fine-grained processes of individual trees, humans, or wildlife. Instead, ecological systems, or sets of a mix of species and landscape conditions, must be represented. This follows the general approach of prior landscape models. Further, generalized implementation of our proposed approach by focusing on the data layers is expected to yield significant value.

The base layers of the framework will revolve around a simple terrestrial vegetation prediction engine. The engine will work using available data as follows:

1. Climate data will be procured from online sources. Where insufficient temporal resolution exists, a linear (or other best fit) model will be used to temporally interpolate atmospheric regimes. This, ofcourse, assumes that the climate conditions are changing monotonically over time for any given location, but does allow for geographic variability.

2. Terrestrial ecological data can be procured from avariety of datasets, but NatureServe provides a substantial amount of data already categorized for ecological systems, and will be used here. Further, vegetation species level information will be extracted for each ecological system and used as part of a Holdridge Life Zone shifting approach during the dynamic simulation. The 
compositions of ecological systems will be used to temporally and spatially reclassify the map based on different atmospheric inputs.

3. Aquatic ecological systems will be spatially "blocked" from further modeling due to the complexity and hydrologic dependence of these systems. Future efforts could incorporate these landscapes provided sufficient hydrologic forcing can be enumerated over time.

4. Ecological regions that are part of an "urban" regime will be grown using historic growth-rate trends in population density. By assuming a constant growth rate, urban areas will be expanded to represent possible future conditions of urban expansion.

5. Finally, connectivity of the environment is a precursor to understanding the movement of vegetation species and future ecological system states. Possible connectivity will be assessed by evaluating urban areas, aquatic areas, and areas of high elevation as "natural" impediments to vegetation shifts. By representing the landscapes as a gridded mesh, a connectivity computation will be made for each grid cell to assess its weighted connectivity to all the other cells. This will be done simplistically as the inverse distance for a set of possible cost-paths. This will prioritize those cells "less costly" to reach while limiting the possibility of drastic (unrealistic) spreading of ecological systems.

Once the base vegetation layer information has been computed, matrices will be developed to represent the expected distributions of species. First, a cooperation matrix will be developed that scores each species ability to thrive symbiotically. Second, a competition matrix will be developed that scores each species on which species is more "dominant" or likely to exclude other species. These will be developed through expert opinion. These matrices will be used to determine which species is most likely to survive at a given, otherwise suitable, location. Suitable locations are those locations with an ecological system that is supportive of the specific wildlife species in question. By evaluating competition and cooperation, a probabilistic occurrence model can be used to artificially limit range expansion due to interactions between the wildlife themselves.

Using this simplistic approach, we expect the model to roughly predict a range of possible outcomes given future conditions. Admittedly predictive modeling only serves as a guide, or expression, of expert opinion. Ultimately, domain scientists must still condense the model's output into meaningful insights that can guide the decision makingprocess.

CONCLUSION: The USACE continually strives to improve habitat restoration on projectlands, but there is a need to predict how species distributions will shift in the future in response to environmental variability resulting from $\mathrm{CC}$. This technical note outlines numerous tools and existing datasets that can assist in determining how species distributions will change over time. Several organizations such as NatureServe and Climate Wizard provide an enormous amount of data ranging from individual species to entire ecosystems, as well as climatic data necessary for predicting future changes. The proposed methodological framework will provide the USACE with models that have the capacity to inform future decision-making. Incorporating integrated assessment modes, climate models, species distribution models, and ecological niche models while also handling uncertainty within these models will provide a working framework that is useful information for project managers as they plan for ecosystem restoration projects. Without the information on how habitats are likely to change, project managers may implement restoration 
efforts that may fail in the future. Knowledge that is gained from the predictive models will help ensure that restoration on project sites are successful for years to come.

POINTS OF CONTACT: For additional information, contact Dr. Jacob Jung (601-634-5242, Jacob.F.Jung@usace.army.mil), Austin Davis (601-634-3687), Austin.V.Davis@usace.army.mil) or the manager of the Ecosystem Management and Restoration Research Program, Dr. Trudy Estes (601-634-2125, Trudy.J.Estes@usace.army.mil). This technical note should be cited as follows:

Davis, A., A. Fuentes, J. F. Jung, E. Britzke, and R. A. Fischer. 2019. "Predicting Wildlife Species Distribution Response to Ecological Shifts" EMRRP Technical Notes Collection ERDC/TN EMRRP-EI-05. Vicksburg, MS: U.S. Army Engineer Research and Development Center. https://emrrp.el.erdc.dren.mil/

\section{REFERENCES}

Ackerly, D. D. 2003. Community assembly, niche conservatism, and adaptive evolution in changing environments. International Journal of Plant Sciences 164(S3):s165-s184. doi:10.1086/368401.

Araujo, M., R. Pearson, W. Thuillers, and M. Erhard. 2005. Validation of species-climate impact models under climate change. Global Change Biology 11(9)1504-1513. https://doi:10.1111/j.1365-2486.2005.001000.x.

Beaumont, L. J., L. Hughes, and M. Poulsen. 2005. Predicting species distributions: use of climatic parameters in BIOCLIM and its impact on predictions of species' current and future distributions. Ecological Modelling 186(2) 250-269. https://doi.org/10.1016/j.ecolmodel.2005.01.030.

Beaumont, L. J., L. Hughes, and A. J. Pitman. 2008. Why is the choice of future climate scenarios for species distribution modelling important? Ecology Letters 11(11):1135-1146. https://doi.org/10.1111/j.1461$\underline{0248.2008 .01231 . x}$.

Bennett, B., and C. Fellbaum. 2006. On what goes on: The ontology of processes and events. In Formal Ontology in Information Systems: Proceedings of the Fourth International Conference (FOIS 2006) 150(4).

Britzke, E. R., N. R. Beane, A. V. Davis, M. D. Whitby, and S. M. Brasfield. 2014. A Robust, Scalable Framework for Conducting Climate Change Susceptibility Analyses. ERDC/EL TN-14-1. Vicksburg, MS: U.S. Army Corps of Engineers (ERDC).

Cann, A. 2010. Scenario-based strategic planning in the U.S. Army Corps of Engineers Civil Works Program. Washington, DC: Institute for Water Resources White Paper.

Chen, I.-C., J. K. Hill, R. Ohlemuller, D. B. Roy, and C. D. Thomas. 2011. Rapid range shifts of species associated with high levels of climate warming. Science 333(6045):1024-1026. doi:10.1126/science.1206432.

Curry, J. 2014. Uncertain temperature trend. Nature Geoscience 7:83-84.

Dale, V. H., L. A. Joyce, S. McNulty, R. P. Neilson, M. P. Ayres, M. D. Flannigan, P. J. Hanson, L. C. Irland, A. E. Lugo, C. J. Peterson, D. Simberloff, F. J. Swanson, B. J. Stocks, and B. M. Wotton. 2001. Climate change and forest disturbances: Climate change can affect forests by altering the frequency, intensity, duration, and timing of fire, drought, introduced species, insect and pathogen outbreaks, hurricanes, windstorms, ice storms, or landslides. BioScience 51(9) 723-734. https://doi.org/10.1641/0006-3568(2001)051[0723:CCAFD]2.0.CO;2

Donoghue, M. J., and E. Edwards. 2014. Biome shifts and niche evolution in plants. Annual Review of Ecology, Evolution, and Systematics 45:547-572. https://doi.org/10.1146/annurev-ecolsys-120213-091905.

Foden, W., G. M. Mace, J. -C. Vie, A. Angulo, S. H. Butchart, L. DeVantier, Turak, H. T. Durblin, A. Gutsche, S. Stuart, E. Turak. 2008. Species susceptibilty to climate change impacts. In J.-C. Vie, C. Hilton-Taylor, \& S. N. Stuart (Eds.), Wildlife in a Changing World: An analysis of the 2008 IUCN Red List of Threatened Species (7787). Gland, Switzerland: IUCN.

Giorgi, F. 2005. Climate change prediction. Climatic Change 73(3):239-265. 
Girvetz, E. H., C. Zganjar,G. T. Raber, E. P. Maurer, P. Kareiva, and J. J. Lawler. 2009. Applied climate-change analysis: The climate wizard tool. PLOS ONE 4(12):e8320.https://doi.org/10.1371/journal.pone.0008320.

Gonzalez, P., R. P. Neilson, J. M. Lenihan, and R. J. Drapek. 2010. Global patterns in the vulnerability of ecosystems to vegetation shifts due to climate change. Global Ecology and Biogeography 19(6):755-768. https://doi.org/10.1111/j.1466-8238.2010.00558.x.

Heikkinen, R. K., M. Luoto, M. B. Araujo, R. Virkkala, W. Thuiller, and M. T. Sykes. 2006. Methods and uncertainties in bioclimatic envelope modelling under climate change. Progress in Physical Geography 30(6):1-27. https://doi.org/10.1177/0309133306071957

Hoffmann, A. A., and C. M. Sgro. 2011. Climate change and evolutionary adaptation. Nature 470:479-485.

Intergovernmenatl Panel on Climate Change (IPCC). 2007. Climate change 2007: The physical science basis. In Contribution of working group I to the fourth assessment report of the Intergovernmental Panel on Climate Change. United Kingdom and New York, USA: Cambridge University Press.

Klein, R, J.T. 2004. Approaches, methods and tools for climate change impact, vulnerability and adaptation assessment. Keynote Lecture to the In-Session Workshop on Impacts of, and Vulnerability and Adaptation to, Climate Change, Buenos Aires, Argentina: 8 December 2004.

McCarthy, J. J., O. F. Canziani, N. A. Leary, D. J. Dokken, and K. S. White. (Eds.). 2001. Climate Change 2001: Impacts, Adaptation, and Vulnerability. Cambridge, UK: Cambridge University Press.

Moss, R., J. Edmonds, K. Hibbard, M. Manning, S. Rose, D. P. van Vuuren, T. R. Carter, S. Emori, M. Kainuma, T. Kram, G. A. Meehl, J. F. B. Mitchell, N. Nakicenovic, K. Riahi, S. J. Smith, R. J. Srouffer, A. M. Tomsom, J. P Weyant and T. J. Wilbanks. 2010. The next generation of scenarios for climate change research and assessment. Nature 463(11):747-756.

NatureServe. 2017. NatureServe: Data, Maps \& Tools. Accessed on 15 March 2019: http://www.natureserve.org/conservation-tools/data-maps-tools

Overland, J., and M. Wang, M. 2010. Large-scale atmospheric circulation chagnes are associated with the revent loss of Arctic sea ice. Tellus A Dynamic Meterology and Oceanography 62A:1-9. https://doi.org/10.1111/j.1600$\underline{0870.2009 .00421 . \mathrm{x}}$

Poulter, B., P. Ciais, E. Hodson, H. Lischke, F. Maignan, S. Plummer, and N. E. Zimmermann. 2011. Plant functional type mapping for earth system models. Geoscientific Model Development 4:993-1010. https://doi.org/10.5194/gmd-4-993-2011

Pultar, E., M. Raubal, T. J. Cova, and M. F. Goodchild. 2009. Dynamic GIS case studies: Wildfire evacuation and volunteered geographic information. Transactions in GIS 13(s1):85-104. https://doi.org/10.1111/j.1467$\underline{9671.2009 .01157 . x}$

Randall, D. A., R. A. Wood, S. Bony, R. Colman, T. Fichefet, J. Fyfe, V. Kattsov, A. Pitman, J. Shukla, J. Srinivasan, R. J. Stouffer, A. Sumi, and K. E. Taylor. 2007. Chapter 8: Climate models and their evaluation. In: Climate Change 2007. The Physical Science Basis. United Kingdom.

Real, R., A. L. Marquez, J. Olvero, and A.Estrada. 2010. Species distribution models in climate change scenarios are still not useful for informing policy planning: an uncertainty assessment using fuzzy logic. Ecography 33(2):304314. https://doi.org/10.1111/j.1600-0587.2010.06251.x

Schwanitz, V. J. 2013. Evaluating integrated assessment models of global climate change. Environmental Modelling \& Software 50:120-131. https://doi.org/10.1016/j.envsoft.2013.09.005

Shepherd, T. G. 2014. Atmospheric circulation as a source of uncertainty in climate change projections. Nature Geoscience 7:703-708.

Teutschibein, C., and J. Seibert. 2012. Bias correction of regional climate model simulations for hydrological climatechange impact studies: Review and evaluation of different methods. Journal of Hydrology 456-457:23-29. https://doi.org/10.1016/j.jhydrol.2012.05.052.

Thomas, C. D. 2010. Climate, climate change and range boundaries. Diversity and Distributions 16(3):488-495. https://doi.org/10.1111/j.1472-4642.2010.00642.x 
Turner, M. G. 1989. Landscape ecology: the effect of pattern on process. Annual review of Ecology and Systematics 20:171-197. https://doi.org/10.1146/annurev.es.20.110189.001131.

Twidwell, D., B. W. Allred, and S. D. Fuhlendorf. 2014a. Summary of a national-scale assessment of the ecological site description (ESD). Rangelands 36(4):13-17. https://doi.org/10.2111/Rangelands-D-14-00029.1.

Twidwell, D., C. L. Wonkka, C. A. Taylor Jr., C. B. Zou, J. J. Twidell, and W. E. Rogers. (2014b). Drought-induced woody plant mortality in an encroached semi-arid savanna depends on topoedaphic factors and land management. Applied Vegetation Science 17(1):42-52. https://doi.org/10.1111/avsc.12044|.

van Vuuren, D. P., J. Lowe, E. Stehfest, L. Gohar, A. Hof, C. Hope, R. Warren, M. Meinshausen, and G.-K Plattner. 2009. How well do integrated assessment models simulate climate change? Climate Change 104(2):1-31.

Walther, G.-R., E. Post, P. Convey, A. Menzel, C. Parmesan, T. J. Beebee, J-M Fromentin, O. Hoegh-guldberd, and F. Bairlein. 2002. Ecological responses to recent climate change. Nature 416:389-395.

Watt, A. S. 1947. Pattern and process in the plant community. Journal of Ecology 35(1/2):1-22. https://www.jstor.org/stable/2256497.

NOTE: The contents of this technical note are not to be used for advertising, publication, or promotional purposes. Citation of trade names does not constitute an official endorsement or approval of the use of such products. 